\title{
COVID-19 by SARS-CoV-2: a Brief Review on the Origins, Pathogenesis and Epidemiology
}

\author{
Anamaria Ioana PAȘTIU', Vlad COCOSTÎRC ${ }^{1 *}$, Carmen TURCU ${ }^{1}$, \\ Felix LUCACI ${ }^{1}$, Dana Liana PUSTA ${ }^{1}$
}

\author{
${ }^{1}$ Faculty of Veterinary Medicine, University of Agricultural Sciences and Veterinary Medicine Cluj-Napoca, Calea \\ Mănăştur 3-5, 400372, Cluj-Napoca, Romania \\ * Corresponding author: Vlad COCOSTÎRCe-mail:vlad.cocostirc@usamvcluj.ro
}

REVIEW

\begin{abstract}
December 2019 was marked by the emergence of a novel human coronavirus (SARS-CoV-2) in Wuhan, China, which causes a variety of symptoms, commonly known as COVID-19. The high contagiousness, rapid worldwide spread and case fatality rate have led to a sharp increase in number of infected persons and related deaths, which subsequently resulted in the recognition of the COVID-19 outbreak as a pandemic by the World Health Organization. SARS-CoV-2 is an ongoing challenge not only for the healthcare professional but also for the general population. The aim of this literature review is to summarize the currently available data on COVID-19 regarding the origins, pathogenesis and epidemiology.
\end{abstract}

Keywords: COVID-19; SARS-CoV-2; origin; pathogenesis; epidemiology.

Received: 06 October 2020

Accepted: 14 April 2021

Published: 14 May 2021

DOI:

10.15835/buasvmcn-vm:2020.0040

@) $\Theta \Theta \Theta(\odot) 2021$ Authors. The papers published in this journal are licensed under the Creative Commons Attribution-NonCommercialNoDerivatives 4.0 International License

\section{INTRODUCTION}

On $31^{\text {th }}$ December 2019 in China, The Health Commission of Hubei province announced a cluster of unexplained cases of pneumonia (Chan et al., 2020). All cases were linked to Wuhan's Huanan Seafood Wholesale Market where trades with living animal species like bats, poultry or snakes are made (Sohrabi et al., 2020).

On $9^{\text {th }}$ January 2020, a new coronavirus was identified and the World Health Organization (WHO) called it SARS-CoV-2 (Severe Acute Respiratory Syndrome Coronavirus 2) which is responsible for COVID-19 (Novel Coronavirus Disease 2019) (Amodio et al., 2020).

Preliminary data suggests the reported death rate ranges from $1 \%$ to $2 \%$ depending on the study and country (Cascella et al., 2020). First death caused by SARS-CoV-2 was registered on 9th January 2020, in China (European Centre for Disease Prevention and Control, 2020).

Up until the 24th of January, this new virus had 887 confirmed cases and 26 deaths in Wuhan, in the nearest cities and in foreign countries (Yu et al., 2020). In a couple of days countries like Thailand, Japan or South Korea announced cases of SARS-CoV-2 diagnosed in people who just returned from Wuhan (Singhal, 2020). On the same day, the first case of COVID-19 was reported in Europe, in France (Linka et al., 2020).

On 30 January 2020, the WHO officially declared the SARS-CoV-2 epidemic as a public health emergency of international concern (Sohrabi et al., 2020).

On 18 February, all around the world 75.199 people were positive for SARS-CoV2 infection and 2009 deaths were declared because of the novel virus. Two days later human-to-human transmission was officially confirmed (Deng and Peng, 2020). 
On 11 March, the WHO declared the SARS-CoV-2 outbreak a pandemic (World Health Organization, 2020a). As a result, many countries have taken unprecedented measures to stop the infection with the new virus: social distancing was applied, therefore schools, universities, and most companies were closed, with significant consequences on global economy (Mehta et al., 2020).

European continent was declared the epicenter of COVID-19 pandemic by the WHO on 13 March, because there were more reported cases and deaths than the combined rest of the world (Linka et al., 2020). Until the 18th of March, in Europe over 250 million people were in lockdown. Like in Wuhan, also in Europe the travel restrictions were implemented late, to a week after each country reported cases (Linka et al., 2020).

Generally, the clinical symptoms of SARS-CoV-2 infection are dry cough, sore throat, fever, dyspnea and bilateral infiltrates on imaging, while high risk patients, can develop pulmonary edema, severe pneumonia, septic shock or organ failure (Sohrabi et al., 2020). The average incubation period for the novel coronavirus is about 5 days. From the first symptom to a possible death, there can be between 6 to 40 days, with an average of 14 days and the evolution is more severe for patients with a compromised immune system (Rothan and Byrareddy, 2020).

From current statistics, the case fatality rate for COVID-19 is higher than that for seasonal influenza but is lower than the case fatality rate for SARS and MERS, also COVID-19 is more infectious than both of them ( Zhang et al., 2020).

\section{ORIGINS}

In the 1960s human coronaviruses were first described. In 1965, from the nasal discharge of patients with flu symptoms human coronavirus was firstly isolated (Tyrrell and Bynoe, 1965). Coronaviruses are considered benign pathogens causing, among other, common cold and mild respiratory issues (Andersen et al., 2020).

Coronaviruses are members of the Order - Nidovirales, the family - Coronaviridae and the subfamily - Coronavirinae. The Coronavirinae subfamily has 4 genera: Alphacoronavirus, Betacoronavirus, Gammacoronavirus and Deltacoronavirus. Alphacoronaviruses and Betacoronaviruses are usually causing gastroenteritis in animals and respiratory issues in humans (Cui et al., 2019).

Coronavirus is a single stranded RNA virus ranging from $60 \mathrm{~nm}$ to $140 \mathrm{~nm}$ in diameter, which under electron microscopy appears like a crown due to the spikes over its surface (Singhal, 2020).

Throughout history there were two events when the crossover of animal betacoronavirus to human resulted in severe diseases. In 2002, in China and Hong Kong, a betacoronavirus with origin in bats crossed over to humans through palm civet cats as intermediary host, giving birth to severe acute respiratory syndrome coronavirus (SARS-CoV), with a mortality rate of almost 11\%. In 2012, in Saudi Arabia, also a betacoronavirus with origin in bats and dromedary camels as intermediary host crossed over to humans causing Middle East Respiratory Syndrome Coronavirus (MERS-CoV), with a mortality rate of almost 34\% (Chan-Yeung and Xu, 2003).

SARS-CoV-2 differs from SARS-CoV and MERS-CoV as transmission efficiency, mortality rate, and disease spectrum. Out of a desire to avoid any unnecessary reason for panic, especially in Asia, which was heavily affected by the epidemic of SARS in 2003, the WHO intends to avoid the word SARS and named the new disease as COVID-19 (the coronavirus disease 2019) which is caused by SARS-CoV-2 virus (World Health Organization, 2020b).

The source of the SARS-CoV-2 infection seems to be the bats (Rhinolophus affinis spp). SARS-CoV-2 is $96 \%$ identical to a bat's coronavirus at the whole-genome level, and bat coronaviruses infection had similar patterns with the novel coronavirus. There are studies that showed that the pangolin can be a potential host for the novel coronavirus (L. Wang et al., 2020). Pangolins are known for the fact that they are illegally trafficked, being used as a food source, or in Chinese traditional medicine. Two lineages of coronaviruses were found in pangolins, and these lineages were also related to COVID-19, which suggests that these animals can be a reservoir for the novel virus (Lam et al., 2020). Some studies found out that also minks may be intermediate hosts for the SARS-CoV-2 (Cheng and Shan, 2020). Some researchers explained that the new coronavirus may be the recombinant virus of the snake coronavirus and the bat coronavirus (Xie and Chen, 2020). So, like bats, minks and pangolins, snakes can be as well cataloged as reservoirs of viruses for human infection (D. Wu et al., 2020).

There were genetic studies that confirmed that SARS-CoV-2 was not derived for any other previously described coronaviruses (Andersen et al., 2020). Shan Liu et al. (Liu et al., 2020) and Pei Hao et al. (Hao et al., 2020) also demonstrated in their studies that SARS-CoV-2 was not a laboratory made virus. Therefore, the theory that the novel coronavirus was obtained in a laboratory seems improbable.

It is known that wild animals can be a virus source, but the main source of infection were the patients with SARS-CoV2 infection, especially the asymptomatic ones (L. Wang et al., 2020).

In humans, SARS-CoV-2 was first isolated from Wuhan's Huanan Seafood Wholesale Market workers. There are studies that argue about the presence of the novel virus before December 2019 and its possible misdiagnosis as a common cold ( Zhang et al., 2020). In France, a retrospective study showed that one patient was hospitalized with hemoptysis, cough, headache fever, and bilateral ground-glass opacities on CT scan in December 2019, a month before the first confirmed case. Four months later a respiratory sample from the same patient was tested for COVID-19 and the result was positive (Deslandes et al., 2020).

A phylogenetic analysis of 103 genomes was made and the result showed that SARS-CoV-2 owns two major coexisting lineages, such as L-type and S-type (Tang et al., 2020). In Wuhan city, the L-type ( 70\%) was the major type and presented 
a higher rate of transmission being more aggressive. The S-type ( 30\%) was the minor type. In the other countries, the Ltype had a lower frequency compared to the S-type (96.3\% for the L-type and 3.7\% for the S-type in Wuhan while outside of Wuhan the percent of the L-type was lower, of almost 62\%). It is not clear enough whether the immunity acquired against one lineage will be effective against the other one and, if a patient who had recovered from an infection with one of the types may suffer a new infection with the other type. The future vaccine needs to involve both lineages (Kakodkar et al., 2020; Tang et al., 2020).

\section{PATHOGENESIS}

The pathological features of COVID-19 greatly resemble those seen in SARS and MERS coronavirus infection (Ng et al., 2016; Xu et al., 2020).

Coronaviruses (CoVs) are enveloped, positive-stranded RNA viruses with nucleocapsid. For addressing pathogenetic mechanisms of SARS-CoV-2, its viral structure and genome must be taken into consideration. In CoVs, the genomic structure is organized in a RNA of approximately $30 \mathrm{~kb}$ length, the largest known RNA viruses, and with a 5'-cap structure and 3'-poly-A tail. Different coronaviruses present special structural and accessory proteins (Perlman and Netland, 2009).

Pathophysiology and virulence mechanisms of coronaviruses, and therefore also of SARS-CoV-2 have links to the function of the non-structural proteins and structural proteins. For instance, research underlined that non-structural protein was able to block the host innate immune response. Among functions of structural proteins, the envelope has a crucial role in virus pathogenicity as it promotes viral assembly and release. However, many of these features have not yet been described (Lei et al., 2018).

Among the structural elements of coronaviruses, there are the spike glycoproteins composed of two subunits, S1 and S2. Homotrimers of S proteins compose the spikes on the viral surface, guiding the link to host receptors (Song et al., 2018).

Researchers had published several SARS-CoV-2 gene sequences in international gene banks such as GenBank (NCBI - GenBank, SARS-CoV-2 Resources, 2020). This gene mapping is of fundamental importance. It allows researchers to trace the phylogenetic tree of the virus and, above all, the recognition of strains that differ according to the mutations. According to recent research, a spike mutation, which probably occurred in late November 2019, triggered jumping to humans. Angeletti et al. (Angeletti et al., 2020) compared the SARS-CoV-2 gene sequence with that of SARS-CoV. They analyzed the transmembranal helical segments in non-structural protein 3 and found that position 723 presents a serine instead of a glycine residue, while the position 1010 is occupied by proline instead of isoleucine. The key for explaining potential disease relapses was the matter of viral mutations (Angeletti et al., 2020).

Further research will be needed to determine the structural characteristics of SARS-CoV-2 that underlie the pathogenetic mechanisms. Compared to SARS, for example, initial clinical data showed less extra respiratory involvement (Cascella et al., 2020).

The pathogenic mechanism that produces pneumonia in patients infected with SARS-CoV-2 seems to be particularly complex. So far available data seem to indicate that the viral infection is capable of producing an excessive immune reaction in the host labeled as a 'cytokine storm'. Its effect is extensive tissue damage. The protagonist of this storm is interleukin 6 (IL-6). IL-6 is produced by activated leukocytes and acts on a large number of cells and tissues. IL-6 is able to promote the differentiation of B lymphocytes, promotes the growth of some categories of cells and inhibits the growth of the others. IL-6 also stimulates the production of acute phase proteins and plays an important role in thermoregulation, in bone maintenance and in the functionality of the central nervous system. Moreover, IL-6 increases during inflammatory diseases, infections, autoimmune disorders, cardiovascular diseases and some types of cancer. IL-6 is also implicated into the pathogenesis of the cytokine release syndrome (CRS) that is an acute systemic inflammatory syndrome characterized by fever and multiple organ dysfunction (Cascella et al., 2020).

The mechanism of acute myocardial injury caused by SARS-CoV-2 infection might be related to angiotensinconverting enzyme 2 (ACE2). ACE2 is widely expressed not only in the lungs but also in the cardiovascular system. Other proposed mechanisms of myocardial injury include a cytokine storm triggered by an imbalanced response by type 1 and type $2 \mathrm{~T}$ helper cells. In consequence, respiratory dysfunction and hypoxaemia caused by COVID-19, resulting in damage to myocardial cells (Huang et al., 2020).

\section{EPIDEMIOLOGY}

\section{Evolution}

The cases of pneumonia with unknown etiology were first reported in Wuhan City, Hubei, China, in late December 2019 (Lu et al., 2020). Since 20 January 2020, the date by which 282 COVID-19 cases from four countries were reported (China - 278 cases, Thailand - 2 cases, Japan and the Republic of Korea - 1 case), the novel coronavirus has been spread almost worldwide, that means 215 countries from six continents (Worldometers, 2020). The up-to-date evolution of COVID-19 cases based on WHO data are represented in Figure 1.

COVID-19 produced by SARS-CoV-2, also known as 2019-nCoV or hCoV-19, was declared by WHO to be a Global public health emergency (30 January 2020), and only 30 days later as a controllable pandemic (11 March 2020). In 
European region the first country with COVID-19 confirmed case was France (24 January 2020), followed three days later by Germany. The next European countries affected by the novel coronavirus were Finland, Italy, Russian Federation, Spain, UK (World Health Organization, 2020c). Despite the authorities' efforts, SARS-CoV-2 has spread rapidly throughout Europe, mainly through infected individuals who have traveled from China, and later from other countries where the disease has been confirmed (Candido et al., 2020).

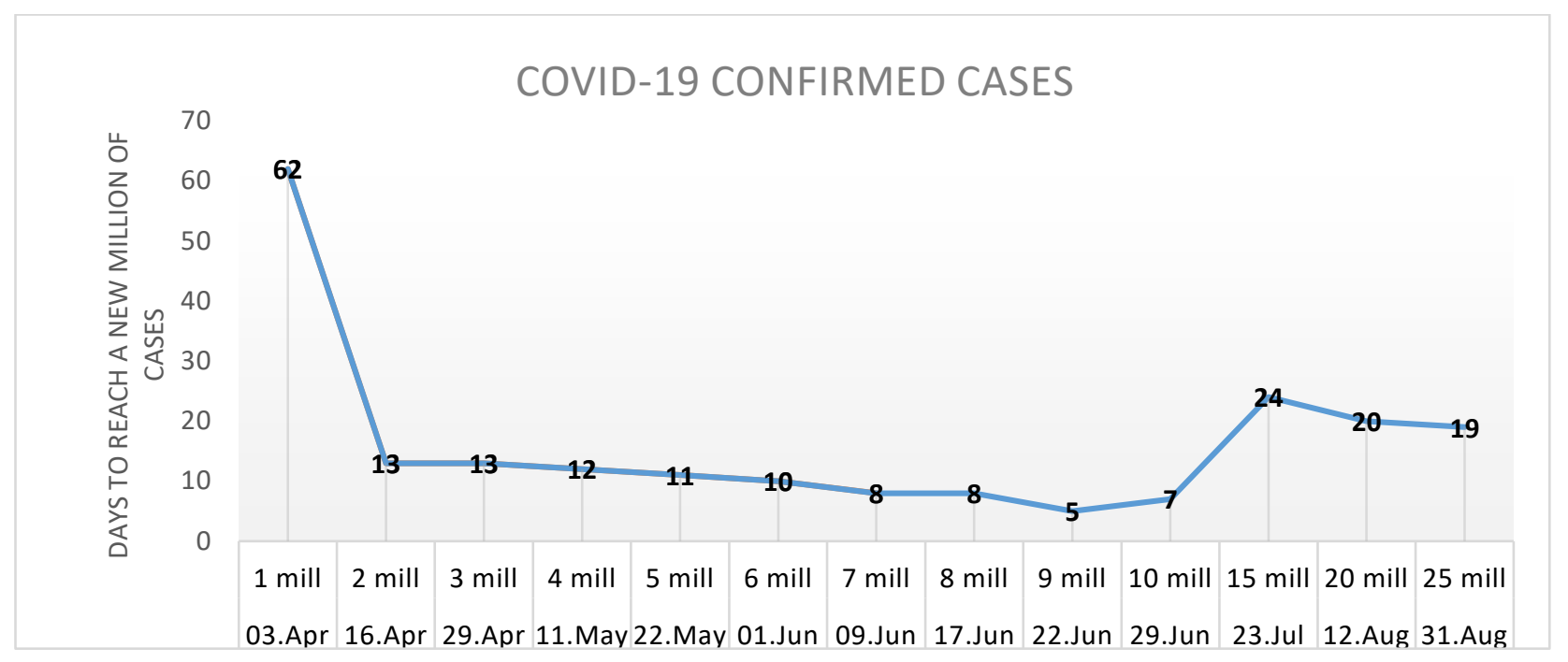

Figure 1. The evolution of COVID-19 confirmed cases based on WHO data (World Health Organization, 2020c).

On 26th of April 2020 (the date we started this study), globally, 2.938.733 COVID-19 cases were confirmed and 203.798 deaths, of which only in Europe 1.314.666 confirmed cases and 119.463 deaths (World Health Organization, 2020d). To date, 19 September 2020, globally, 30.896 .467 cases were diagnosed with SARS-CoV-2, and the number of deaths reached 959.343. In Europe, the virus was spread in 48 countries, there were 4.396 .445 confirmed cases and 215.890 deaths. Between European countries, Russia, Spain, France, UK, Italy, Germany, followed by Ukraine, Romania, Belgium, Netherlands and Sweden recorded the highest number of cases, while some countries from East Europe remained moderately affected (Moldova, Serbia, Bulgaria, Hungary, Greece) (World Health Organization, 2020c). Considering these data, Europe has been severely affected by this pandemic and will continue to be.

There is not a standard pattern in the evolution of this pandemic. The situation differs from country to country, depending on the policy adopted and the receptivity of the population to the prevention measures taken. Major government measures such as self-isolation, social distancing, prohibition of public events, closure of restaurants, schools, have had a decisive impact in COVID-19 evolution in each country (Flaxman et al., 2020). Additionally, the countries less affected were those in which quarantine measures were taken since the first confirmed cases of COVID-19, compared to those countries where the policy was to immunize the population through exposure to the virus.

\section{Transmission}

Considering the resistance of the novel coronavirus in the environment, up to 3 hours in aerosols, up to 4 hours on copper, up to 24 hours on cardboard and up to 72 hours on plastic and stainless steel (Van Doremalen et al., 2020), humanto-human transmission, via respiratory droplets and contact, remains the main important route for worldwide virus spread (Guo et al., 2020). Asymptomatic carriers, including newborns and children (Rawat et al., 2020), and SARS-CoV-2 infected individuals during incubation period, before the onset of symptoms, represented the most important virus source (Rothe et al., 2020; P. Yu et al., 2020), although there were studies which reported that the infectivity of some asymptomatic carriers may be low (Gao et al., 2020). SARS-CoV-2 humans-to-animals transmission was demonstrated by RT-PCR, serology and sequencing of the viral genome (Sit et al., 2020), but as we know so far, no animal-to-humans virus transmission has been reported.

To assess the degree of risk posed by the novel coronavirus SARS-CoV-2, the following parameters must be considered: the transmissibility rate (R0) or the number of individuals that a SARS-CoV-2 positive case can infect; the incubation rate; case fatality rate (CFR) or the percentage of deaths from the total number of SARS-CoV-2 positive cases; the possibility of asymptomatic transmission; antibodies anti-SARS-CoV-2 neutralization potency.

SARS-CoV-2 presented a rate of transmissibility between 2.24 and 3.58 (Zhao et al., 2020), and a CFR closer to $3 \%$ (C. Wang et al., 2020). The highest CFR was recorded in Italy (7.2\%), which is substantially higher than in China (2.3\%) (Onder et al., 2020). Compared with SARS (Severe acute respiratory syndrome) which evolved in 2002-2003, SARS-CoV2 presented a higher R0 (2.0 for SARS), and a lower CFR (SARS was 10\%). The incubation period of the COVID-19 
varied between 2 and 14 days, with a mean of 5.2 days (Li et al., 2020). A longer incubation period may suggest a double exposure.

The risk factors associated with the novel coronavirus were age, comorbidities, sex, and health education. People of all ages can be infected by SARS-CoV-2. Elderly and the people with chronic comorbidities seems to be more vulnerable to develop severely ill and death (Chen et al., 2020; Zheng et al., 2020), while neonates, infants, and children were asymptomatic or develop mild forms (Abduljalil and Abduljalil, 2020; Rothe et al., 2020). The men and women had an equal chance of contracting the virus, but men, regardless of age, were more at risk to develop severe ill and death (Salje et al., 2020). The majority of the fatalities had occurred in patients over 50 years of age (Cascella et al., 2020). Wu and McGoogan (Wu and McGoogan, 2020) had mentioned that no fatal cases occurred in patients aged between 9 years or younger. The most common comorbidities of the patients hospitalized diagnosed with COVID-19 were hypertension, diabetes, coronary heart disease and obesity (Ruan et al., 2020; Zhou et al., 2020).

Epidemiologically, considering the SARS-CoV-2 asymptomatic carriers, the study of antibodies and their dynamics is extremely useful to evaluate the degree of spread of the infection in a population post-exposure. These means, to evaluate the number of people who came in contact with the virus and who developed a specific immune response. Serological screening can provide a clear picture of certain aspects of the disease: the asymptomatic case rate; the degree of transmissibility; the type of immunity acquired post-infection, temporary or permanent; if the anti-SARS-CoV-2 antibodies are neutralizing. Virus neutralizing antibodies can occur after natural infection or vaccination, and they may have an important role in pandemic evolution, by limiting the spread of infection (Manenti et al., 2020). What we know so far is that IgM and IgG antibodies appear between 7 and 12 days after the onset of symptoms (Hoffman et al., 2020; Zhang W. et al., 2020) and the seroconversion of the both types of antibodies occurs relatively simultaneously (Hsueh et al., 2004).

\section{Mortality in COVID-19}

The obtained median time from illness onset to discharge was 22 days, whereas the median time to death was between 14 and 18.5 days, this period may vary on age and pre-existing comorbidities (Wu et al., 2020; Rothan and Byrareddy, 2020; Zhou et al., 2020). Ruan et al. (2020) reported that the distribution of survival time from disease onset to death showed two peaks. The first one at approximately 14 days and the second one at approximately 22 days. The median time from illness onset to invasive mechanical ventilation was 14.5 days. Median duration of viral shedding was 20 days in survivors, but SARS-CoV-2 was detectable until death in non-survivors. The longest observed duration of viral shedding in survivors was 37 days (Zhou et al., 2020).

Approximately half of the critical patients affected by preexisting comorbidities such as cardiovascular disease, diabetes, chronic respiratory disease, and oncological diseases, died (Abduljalil and Abduljalil, 2020; Zhou et al., 2020). The repeatedly reported complications were sepsis, followed by respiratory failure, acute respiratory distress syndrome (ARDS), heart failure, and septic shock. The secondary infections and ventilator-associated pneumonia were more often observed in non-survivors than in survivors (Ruan et al., 2020). Age, lymphopenia, leukocytosis, and elevated ALT, lactate dehydrogenase, high-sensitivity cardiac troponin I, creatine kinase, serum ferritin, IL-6, prothrombin time, creatinine, and procalcitonin were also associated with death (Manenti et al., 2020; Ruan et al., 2020). Data showed increasing odds of inhospital death were associated with high Sequential Organ Failure Assessment (SOFA) score, d-dimer greater than 1 $\mu \mathrm{g} / \mathrm{mL}$, elevated inflammatory indicators in the blood (Ruan et al., 2020; Zhou et al., 2020). COVID-19 mortality might be due to virus-activated "cytokine storm syndrome" or fulminant myocarditis (Ruan et al., 2020).

Considering the high CFR registered, Italy represented a good example for analysis of the mortality pattern. Based on the data up to 17 th of March (1625 deaths/22512 cases), the overall fatality rate of persons with confirmed COVID-19 in the Italian population was 7.2\% (Livingston and Bucher, 2020). First of all, the overall older age distribution in Italy played a significant role in the higher average CFR in Italy compared to other countries such as China (Onder et al., 2020). A second possible explanation for the high Italian CFR may be the way COVID-19-related deaths were identified in Italy. Case-fatality statistics in Italy were based on defining COVID-19-related deaths as those occurring in patients who test positive for SARS-CoV-2 via RT-PCR, independently from preexisting diseases that may have caused death. Defining death from COVID-19 in this way may have resulted in an overestimation of the CFR (Onder et al., 2020). A third possible explanation for the high Italian CFR might be the differing strategies used for SARS-CoV-2 RT-PCR testing. After an initial extensive testing strategy of both symptomatic and asymptomatic contacts of infected patients in a very early phase of the epidemic, testing was limited for asymptomatic people or those who had limited, mild symptoms. This testing strategy resulted in a high proportion of positive results and an apparent increase in the CFR because patients who presented with less severe clinical disease were no longer tested. Overall, CFR changed from $3.1 \%$ on 24 th of February to $7.2 \%$ on 17th of March. Thus, the milder cases with low fatality rate were no longer taken into consideration. Furthermore, considering the evolution of this pandemic the mortality pattern may change (Onder et al., 2020).

\section{CONCLUSIONS}

The novel coronavirus has changed the world from multiple points of view. People have become more conscious of the importance of hygiene and have experienced unprecedented emotions related to social isolation. Even though SARS-CoV2 is the current focus of medical scientists, there are still uncertainties when it comes to the origins, pathogenesis and even epidemiology. Asymptomatic carriers are an ongoing challenge due to their difficult identification and contagiousness. The 
global effort against COVID-19 is confronted with the continuously growing numbers of confirmed cases. Future perspectives should aim to prevent the emergence of similar outbreaks with zoonotic origins.

Author Contributions: A.I.P., V.C., C.T., F.L., D.L.P. prepared the original draft; A.I.P., V.C., D.L.P. reviewed and edited the manuscript; D.L.P. supervised the overall process. All authors have read and agreed to the published version of the manuscript.

Funding Source: This research did not receive any specific grant from funding agencies in the public, commercial, or notfor-profit sectors.

\section{Conflicts of Interest}

The authors declare that they do not have any conflict of interest.

\section{REFERENCES}

1. Abduljalil JM, Abduljalil BM. Epidemiology, genome, and clinical features of the pandemic SARS-CoV-2: a recent view. New Microbes New Infect 2020; 35:100672. Available from: https://doi.org/10.1016/j.nmni.2020.100672.

2. Amodio E, Vitale F, Cimino L, Casuccio A, Tramuto F. Outbreak of Novel Coronavirus (SARS-CoV-2): First Evidences From International Scientific Literature and Pending Questions. Healthcare 2020; 8(1):51. Available from: https://doi.org/10.3390/healthcare8010051.

3. Andersen KG, Rambaut A, Lipkin WI, Holmes EC, Garry RF. The proximal origin of SARS-CoV-2. Nat Med 2020; 26(4):450-2. Available from: https://doi.org/10.1038/s41591-020-0820-9.

4. Angeletti S, Benvenuto D, Bianchi M, Giovanetti M, Pascarella S, Ciccozzi M. COVID-2019: The role of the nsp2 and nsp3 in its pathogenesis. J Med Virol 2020; 92(6):584-8. Available from: https://doi.org/10.1002/jmv.25719.

5. Candido DDS, Watts A, Abade L, Kraemer MUG, Pybus OG, Croda J, et al. Routes for COVID-19 importation in Brazil. J Travel Med 2020; 27(3):taaa042. Available from: https://doi.org/10.1093/jtm/taaa042.

6. Cascella M, Rajnik M, Cuomo A, Dulebohn SC, Di Napoli R. Features, Evaluation and Treatment Coronavirus (COVID-19). StatPearls, Treasure Island (FL): StatPearls Publishing; 2020; Available from: http://www.ncbi.nlm.nih.gov/books/NBK554776

7. Chan JFW, Yuan S, Kok KH, To KK-W, Chu H, Yang J, et al. A familial cluster of pneumonia associated with the 2019 novel coronavirus indicating person-to-person transmission: a study of a family cluster. The Lancet 2020; 395(10223):514-23. Available from: https://doi.org/10.1016/S0140-6736(20)30154-9.

8. Chan-Yeung M, Xu R-H. SARS: epidemiology. Respirology 2003; 8(s1):S9-14. Available from: https://doi.org/10.1046/j.1440-1843.2003.00518.x.

9. Chen H, Guo J, Wang C, Luo F, Yu X, Zhang W, et al. Clinical characteristics and intrauterine vertical transmission potential of COVID-19 infection in nine pregnant women: a retrospective review of medical records. The Lancet 2020; 395(10226):809-15. Available from: https://doi.org/10.1016/S0140-6736(20)30360-3

10. Cheng ZJ, Shan J. 2019 Novel coronavirus: where we are and what we know. Infection 2020; 48(2):155-63. Available from: https://doi.org/10.1007/s15010-020-01401-y

11. Cui J, Li F, Shi ZL. Origin and evolution of pathogenic coronaviruses. Nat Rev Microbiol 2019; 17(3):181-92. Available from: https://doi.org/10.1038/s41579-018-0118-9

12. Deng SQ, Peng HJ. Characteristics of and Public Health Responses to the Coronavirus Disease 2019 Outbreak in China. J Clin Med 2020; 9(2):575. Available from: https://doi.org/10.3390/jcm9020575

13. Deslandes A, Berti V, Tandjaoui-Lambotte Y, Alloui C, Carbonnelle E, Zahar JR, et al. SARS-CoV-2 was already spreading in France in late December 2019. Int J Antimicrob Agents 2020; 55(6):106006. Available from: https://doi.org/10.1016/j.ijantimicag.2020.106006

14. European Centre for Disease Prevention and Control. Update: Cluster of pneumonia cases associated with novel coronavirus - Wuhan, China - 2019. Retrieved on 22 March 2021; Available from: https://www.ecdc.europa.eu/en/news-events/update-cluster-pneumonia-cases-associated-novel-coronavirus-wuhanchina-2019

15. Flaxman S, Mishra S, Gandy A, Unwin HJT, Mellan TA, Coupland H, et al. Estimating the effects of nonpharmaceutical interventions on COVID-19 in Europe. Nature 2020; Available from: https://doi.org/10.1038/s41586020-2405-7 
16. Gao M, Yang L, Chen X, Deng Y, Yang S, Xu H, et al. A study on infectivity of asymptomatic SARS-CoV-2 carriers. Respir Med 2020; 169:106026. Available from: https://doi.org/10.1016/j.rmed.2020.106026

17. Guo YR, Cao QD, Hong ZS, Tan YY, Chen SD, Jin HJ et al. The origin, transmission and clinical therapies on coronavirus disease 2019 (COVID-19) outbreak - an update on the status. Mil Med Res 2020; 7(1):11. Available from: https://doi.org/10.1186/s40779-020-00240-0

18. Hao P, Zhong W, Song S, Fan S, Li X. Is SARS-CoV-2 originated from laboratory? A rebuttal to the claim of formation via laboratory recombination. Emerg Microbes Infect 2020; 9(1):545-7. Available from: https://doi.org/10.1080/22221751.2020.1738279

19. Hoffman T, Nissen K, Krambrich J, Rönnberg B, Akaberi D, Esmaeilzadeh M, et al. Evaluation of a COVID-19 IgM and IgG rapid test; an efficient tool for assessment of past exposure to SARS-CoV-2. Infect Ecol Epidemiol 2020; 10(1):1754538. Available from: https://doi.org/10.1080/20008686.2020.1754538

20. Hsueh PR, Huang LM, Chen PJ, Kao CL, Yang PC. Chronological evolution of IgM, IgA, IgG and neutralisation antibodies after infection with SARS-associated coronavirus. Clin Microbiol Infect 2004; 10(12):1062-6. Available from: https://doi.org/10.1111/j.1469-0691.2004.01009.X

21. Huang C, Wang Y, Li X, Ren L, Zhao J, Hu Y et al. Clinical features of patients infected with 2019 novel coronavirus in Wuhan, China. The Lancet 2020; 395(10223):497-506. Available from: https://doi.org/10.1016/S01406736(20)30183-5

22. Kakodkar P, Kaka N, Baig M. A Comprehensive Literature Review on the Clinical Presentation, and Management of the Pandemic Coronavirus Disease 2019 (COVID-19). Cureus 2020; Available from: https://doi.org/10.7759/cureus.7560

23. Lam TTY, Jia N, Zhang YW, Shum MHH, Jiang JF, Zhu HC, et al. Identifying SARS-CoV-2-related coronaviruses in Malayan pangolins. Nature 2020; Available from: https://doi.org/10.1038/s41586-020-2169-0

24. Lei J, Kusov Y, Hilgenfeld R. Nsp3 of coronaviruses: Structures and functions of a large multi-domain protein. Antiviral Res 2018; 149:58-74. Available from: https://doi.org/10.1016/j.antiviral.2017.11.001

25. Li Q, Guan X, Wu P, Wang X, Zhou L, Tong Y, et al. Early Transmission Dynamics in Wuhan, China, of Novel Coronavirus-Infected Pneumonia. N Engl J Med 2020; 382(13):1199-207. Available from: https://doi.org/10.1056/NEJMoa2001316

26. Linka K, Peirlinck M, Sahli Costabal F, Kuhl E. Outbreak dynamics of COVID-19 in Europe and the effect of travel restrictions. Comput Methods Biomech Biomed Engin 2020; 23(11):710-7. Available from: https://doi.org/10.1080/10255842.2020.1759560

27. Liu SL, Saif LJ, Weiss SR, Su L. No credible evidence supporting claims of the laboratory engineering of SARS-CoV2. Emerg Microbes Infect 2020; 9(1):505-7. Available from: https://doi.org/10.1080/22221751.2020.1733440

28. Livingston E, Bucher K. Coronavirus Disease 2019 (COVID-19) in Italy. JAMA 2020; 323(14):1335. Available from: https://doi.org/10.1001/jama.2020.4344

29. Lu H, Stratton CW, Tang Y. Outbreak of pneumonia of unknown etiology in Wuhan, China: The mystery and the miracle. J Med Virol 2020; 92(4):401-2. Available from: https://doi.org/10.1002/jmv.25678

30. Manenti A, Maggetti M, Casa E, Martinuzzi D, Torelli A, Trombetta CM et al. Evaluation of SARS-CoV-2 neutralizing antibodies using a CPE-based colorimetric live virus micro-neutralization assay in human serum samples. J Med Virol 2020; 92:2096-104. Available from: https://doi.org/10.1002/jmv.25986

31. Mehta N, Mazer-Amirshahi M, Alkindi N, Pourmand A. Pharmacotherapy in COVID-19; A narrative review for emergency providers. Am J Emerg Med 2020; 38(7):1488-93. Available from: https://doi.org/10.1016/j.ajem.2020.04.035

32. NCBI - GenBank, SARS-CoV-2 Resources. Retrieved on 28 May 2020; Available from: https://www.ncbi.nlm.nih.gov/sars-cov-2/

33. Ng DL, Al Hosani F, Keating MK, Gerber SI, Jones TL, Metcalfe MG, et al. Clinicopathologic, Immunohistochemical, and Ultrastructural Findings of a Fatal Case of Middle East Respiratory Syndrome Coronavirus Infection in the United Arab Emirates, April 2014. Am J Pathol 2016; 186(3):652-8. Available from: https://doi.org/10.1016/j.ajpath.2015.10.024

34. Onder G, Rezza G, Brusaferro S. Case-Fatality Rate and Characteristics of Patients Dying in Relation to COVID-19 in Italy. JAMA 2020; Available from: https://doi.org/10.1001/jama.2020.4683

35. Perlman S, Netland J. Coronaviruses post-SARS: update on replication and pathogenesis. Nat Rev Microbiol 2009; 7(6):439-50. Available from: https://doi.org/10.1038/nrmicro2147

36. Rawat M, Chandrasekharan P, Hicar MD, Lakshminrusimha S. COVID-19 in Newborns and Infants-Low Risk of Severe Disease: Silver Lining or Dark Cloud? Am J Perinatol 2020; 37(08):845-9. Available from: https://doi.org/10.1055/s-0040-1710512 
37. Rothan HA, Byrareddy SN. The epidemiology and pathogenesis of coronavirus disease (COVID-19) outbreak. J Autoimmun 2020; 109:102433. Available from: https://doi.org/10.1016/j.jaut.2020.102433

38. Rothe C, Schunk M, Sothmann P, Bretzel G, Froeschl G, Wallrauch C et al. Transmission of 2019-nCoV Infection from an Asymptomatic Contact in Germany. $\mathrm{N}$ Engl J Med 2020; 382(10):970-1. Available from: https://doi.org/10.1056/NEJMc2001468

39. Ruan Q, Yang K, Wang W, Jiang L, Song J. Clinical predictors of mortality due to COVID-19 based on an analysis of data of 150 patients from Wuhan, China. Intensive Care Med 2020; 46(5):846-8. Available from: https://doi.org/10.1007/s00134-020-05991-x

40. Salje H, Tran Kiem C, Lefrancq N, Courtejoie N, Bosetti P, Paireau J, et al. Estimating the burden of SARS-CoV-2 in France. Science 2020; 369(6500):208-211. Available from: https://doi.org/10.1126/science.abc3517

41. Singhal T. A Review of Coronavirus Disease-2019 (COVID-19). Indian J Pediatr 2020; 87(4):281-6. Available from: https://doi.org/10.1007/s12098-020-03263-6

42. Sit THC, Brackman CJ, Ip SM, Tam KWS, Law PYT, To EMW, et al. Infection of dogs with SARS-CoV-2. Nature 2020; Available from: https://doi.org/10.1038/s41586-020-2334-5

43. Sohrabi C, Alsafi Z, O’Neill N, Khan M, Kerwan A, Al-Jabir A, et al. World Health Organization declares global emergency: A review of the 2019 novel coronavirus (COVID-19). Int J Surg 2020; 76:71-6. Available from: https://doi.org/10.1016/j.ijsu.2020.02.034

44. Song W, Gui M, Wang X, Xiang Y. Cryo-EM structure of the SARS coronavirus spike glycoprotein in complex with its host cell receptor ACE2. PLOS Pathog 2018; 14(8):e1007236. Available from: https://doi.org/10.1371/journal.ppat.1007236

45. Tang X, Wu C, Li X, Song Y, Yao X, Wu X, et al. On the origin and continuing evolution of SARS-CoV-2. Natl Sci Rev 2020; 7(6):1012-23. Available from: https://doi.org/10.1093/nsr/nwaa036

46. Tyrrell DAJ, Bynoe ML. Cultivation of a Novel Type of Common-cold Virus in Organ Cultures. BMJ 1965; 1(5448):1467-70. Available from: https://doi.org/10.1136/bmj.1.5448.1467

47. Van Doremalen N, Bushmaker T, Morris DH, Holbrook MG, Gamble A, Williamson BN, et al. Aerosol and Surface Stability of SARS-CoV-2 as Compared with SARS-CoV-1. N Engl J Med 2020; 382(16):1564-7. Available from: https://doi.org/10.1056/NEJMc2004973

48. Wang C, Horby PW, Hayden FG, Gao GF. A novel coronavirus outbreak of global health concern. The Lancet 2020; 395(10223):470-3. Available from: https://doi.org/10.1016/S0140-6736(20)30185-9

49. Wang L, Wang Y, Ye D, Liu Q. Review of the 2019 novel coronavirus (SARS-CoV-2) based on current evidence. Int J Antimicrob Agents 2020; 55(6):105948. Available from: https://doi.org/10.1016/j.ijantimicag.2020.105948

50. World Health Organization. (a). WHO Director-General's opening remarks at the media briefing on COVID-19-11 March 2020; Retrieved on 3 July 2020. Available from: https://www.who.int/dg/speeches/detail/who-director-generals-opening-remarks-at-the-media-briefing-on-covid-19---11-march-2020

51. World Health Organization. (b). Naming the coronavirus disease (COVID-19) and the virus that causes it. Retrieved on 3 July 2020; Available from: https://www.who.int/emergencies/diseases/novel-coronavirus-2019/technicalguidance/naming-the-coronavirus-disease-(covid-2019)-and-the-virus-that-causes-it

52. World Health Organization. (c). World Health Organization Coronavirus Disease (COVID-19) Situation Reports. Retrieved on 22 June 2020; Available from: https://www.who.int/emergencies/diseases/novel-coronavirus2019/situation-reports

53. World Health Organization. (d). Coronavirus Disease 2019 (COVID-19) Situation Report—96. Retrieved on 22 June 2020; Available from: https://www.who.int/docs/default-source/coronaviruse/situation-reports/20200425-sitrep-96covid-19.pdf?sfvrsn=a33836bb_4

54. Worldometers. Worldometer Coronavirus Live Update. Retrieved on 1 June 2020; Available from: https://www.worldometers.info/coronavirus/

55. Wu C, Chen X, Cai Y, Xia J, Zhou X, Xu S, et al. Risk Factors Associated With Acute Respiratory Distress Syndrome and Death in Patients With Coronavirus Disease 2019 Pneumonia in Wuhan, China. JAMA Intern Med 2020; Available from: https://doi.org/10.1001/jamainternmed.2020.0994

56. Wu D, Wu T, Liu Q, Yang Z. The SARS-CoV-2 outbreak: What we know. Int J Infect Dis 2020; 94:44-8. Available from: https://doi.org/10.1016/j.ijid.2020.03.004

57. Wu Z, McGoogan JM. Characteristics of and Important Lessons From the Coronavirus Disease 2019 (COVID-19) Outbreak in China: Summary of a Report of 72314 Cases From the Chinese Center for Disease Control and Prevention. JAMA 2020; 323(13):1239. Available from: https://doi.org/10.1001/jama.2020.2648

58. Xie M, Chen Q. Insight into 2019 novel coronavirus - An updated interim review and lessons from SARS-CoV and MERS-CoV. Int J Infect Dis 2020; 94:119-24. Available from: https://doi.org/10.1016/j.ijid.2020.03.071 
59. Xu Z, Shi L, Wang Y, Zhang J, Huang L, Zhang C, et al. Pathological findings of COVID-19 associated with acute respiratory distress syndrome. Lancet Respir Med 2020; 8(4):420-2. Available from: https://doi.org/10.1016/S22132600(20)30076-X

60. Yu F, Du L, Ojcius DM, Pan C, Jiang S. Measures for diagnosing and treating infections by a novel coronavirus responsible for a pneumonia outbreak originating in Wuhan, China. Microbes Infect 2020; 22(2):74-9. Available from: https://doi.org/10.1016/j.micinf.2020.01.003

61. Yu P, Zhu J, Zhang Z, Han Y. A Familial Cluster of Infection Associated With the 2019 Novel Coronavirus Indicating Possible Person-to-Person Transmission During the Incubation Period. J Infect Dis 2020; 221(11):1757-61. Available from: https://doi.org/10.1093/infdis/jiaa077

62. Zhang J, Liu J, Li N, Liu Y, Ye R, Qin X, et al. Serological detection of 2019-nCoV respond to the epidemic: A useful complement to nucleic acid testing. Infectious Diseases (except HIV/AIDS); 2020; Available from: https://doi.org/10.1101/2020.03.04.20030916

63. Zhang L, Shen F, Chen F, Lin Z. Origin and Evolution of the 2019 Novel Coronavirus. Clin Infect Dis 2020; $71(15): 882-$ 883. Available from: https://doi.org/10.1093/cid/ciaa112

64. Zhang W, Du R-H, Li B, Zheng X-S, Yang X-L, Hu B, et al. Molecular and serological investigation of 2019-nCoV infected patients: implication of multiple shedding routes. Emerg Microbes Infect 2020; 9(1):386-9. Available from: https://doi.org/10.1080/22221751.2020.1729071

65. Zhao S, Lin Q, Ran J, Musa SS, Yang G, Wang W, et al. Preliminary estimation of the basic reproduction number of novel coronavirus (2019-nCoV) in China, from 2019 to 2020: A data-driven analysis in the early phase of the outbreak. Int J Infect Dis 2020; 92:214-7. Available from: https://doi.org/10.1016/j.ijid.2020.01.050

66. Zheng Y-Y, Ma Y-T, Zhang J-Y, Xie X. COVID-19 and the cardiovascular system. Nat Rev Cardiol 2020; 17(5):25960. Available from: https://doi.org/10.1038/s41569-020-0360-5

67. Zhou F, Yu T, Du R, Fan G, Liu Y, Liu Z, et al. Clinical course and risk factors for mortality of adult inpatients with COVID-19 in Wuhan, China: a retrospective cohort study. The Lancet 2020; 395(10229):1054-62. Available from: https://doi.org/10.1016/S0140-6736(20)30566-3 